\title{
Professional career management and personal development for the employees of the Romanian medical system
}

\author{
Catalina-Oana MIRICA (DUMITRESCU) \\ The Bucharest University of Economic Studies, Bucharest, Romania \\ catalina.dumitrescu26@yahoo.com
}

\begin{abstract}
The purpose of this article is to inform as many persons as possible on the present situation of doctors in Romania, to present more theoretical and practical elements that lead to the development of a sustainable career in the Romanian medical system. So I tried to get as much information about the current situation of the medical system, to obtain a certain confirmation of what was said by those working in the system. Gradually, I found out about the hospital problems, the insufficient budget allocated annually by the mismanagement, media campaigns of doctor denigration, the increasingly precarious health conditions of Romanians, the colossal businesses of the pharmaceutical industry, the heavily discussed and postponed Health Law, that managed to pull a lot of people in the street, and many other items that are not only intended to sound an alarm regarding the condition of medical workers in Romania. Besides the researches and the relationships on the medical education status, the situation of available positions, the distribution of doctors, their salaries, the legal and ethical operating framework, I undertook also a study among physicians (especially those being at their early career) to find out the elements that led them to choose this career and what is the current situation of medical career in Romania. For this, I chose questions that reflect the doctors' satisfaction at workplace and how performance is influenced by the satisfaction level obtained from the medical services provided in the Romanian healthcare facilities. The study had both expected results, already knowing the current situation, but also unexpected, given the expectations of doctors. In more detail, there is a large number of young doctors that before thinking about work at a prestigious hospital abroad, think to what extent the current workplace in Romania offers support for family, pension, holidays etc. Thus, we considered appropriate to bring up within the paper the current possibilities for personal development, the personal brand in various mediums of communication. This paper could be a viable support to provide the necessary elements in creating an upward career path for young doctors. This paper aims primarily to present a current situation of the medical system, more statistical data (unfortunately, statistics regarding the Romanian medical system are not very up to date, most information relates to the year 2007-2009 - 2010), but also the Romanian situation seen from outside or media. The situation is far from being optimistic, the presented data are clear signals of alarm on the present status, but we hope that in the end, this paper has managed to arouse the interest of Romanian doctors with potential on the possibilities and opportunities for a career development in the homeland.
\end{abstract}

Keywords: management, career, development, medical system, healthcare organizations.

\section{Introduction}

The desire to deepen this theme is older, the subject being always of interest for the author and his family. According to official and sometimes unofficial sources, the situation of many healthcare establishments was known with their issues and achievements. The most important thing is that along the time we have not managed to find arguments according to which Romanian physicians (but also the auxiliary personnel) having a quite thorough training in the field, proving high professionalism in the relationship with their patients, miss their smile of fulfilment, achievement. 
At the early 2000, there was a feeling of deep joy when I was hearing about relatives or contacts practising in the medical field, that they managed to find very advantageous workplaces, with opportunities of development in various parts of the world. Then, my colleagues and friends that had chosen this career, preferred to develop professionally in other country. At that time I did not have any longer the same feeling of joy since I realized which were the losses personally: besides the affection and closeness of the loved persons, also the possibility to be cured in the origin country by the best professionals in the unfortunate case of being taken ill.

Regardless the field of activity, Romanian people are known for their learning and adaptation capacity, therefore there is also a great demand of Romanian manpower on the medical labour market abroad.

Another issue approach within the paper, considered probably a less important subject by authorities, represents the provision of programmes of career counselling, of following the stages in the physicians career, also the provision of support for personal development.

The salary motivation of physicians and the optimal legal operating framework was another subject greatly discussed the last years, but without certain conclusions and finality.

Even if in the first part of my paper, I presented and elaborated a part of the theoretical support to bring suggestions as for the improvement of the Romanian physicians' career, the existing effective situation differs from the one presented theoretically, being differences also from the situation at the European Union level.

The paper researches showed also differences as for the administrative issues of the healthcare system, such the physicians' distribution per the number of inhabitants, the distribution per public/private, urban/rural as well as the differences regarding the remuneration system for physicians of various parts of the world.

When it comes about the development of a lasting career, we talk about:

Access at continuous development programmes;

Workplaces according to legal standards;

- $\quad$ Balance of work-private life;

- $\quad$ Counselling in any stage of the career;

- Development of satisfaction at the workplace;

- $\quad$ Competitive remuneration systems;

- $\quad$ Specific performance assessment grids for the purpose of managing to draw an ascending trajectory in any career.

After reviewing the statistical data for other states, mainly within the European Union, I found that there were strategies presenting at the greatest extent all elements listed previously, leading to a personal and lasting development of the career. Among these states, we mention Denmark, Sweden and even Greece.

Without many introductions, more or less, everybody knows the Romanian healthcare system and the possibilities to develop a career for the Romanian physicians.

\section{Literature review}

For Romanian people, the career and particularly careerism had a negative connotation, referring to the unscrupulousness in the professional ascent. Career supposed for our parents a top achievement in a qualification selected once in a lifetime. 
Nowadays when the negative connotation of the career changed, career represents the sequence of professions, occupations, jobs, positions exercised along the active life, supposing (sometimes spectacular) occupational fluctuations from one age phase to other.

Any actual career is characterized by the process dynamism, the fact that the individual changes several workplaces (in average 5-7) along his active life" (Tasica, 19971998).

Career management intends to achieve objectives related to: stages of the career development, career planning, responsibilities of the employee and of the manager in developing a career, role of counselling in the career orientation etc.

"Self-knowledge has a very important role in making smart decisions related to the career, but also for holding control on it. This means that you have to assess very well how personality, skills and values overlap for achieving the type of appropriate career for each type of person individually"(Fottler and Bain, 1984, p. 347).

Briefly, the career adaptability is related both to its development and direction and the presence of a flexible attitude is necessary. Teamwork, efficient communication, adaptation to change, positive attitude, continuous skill upgrade, self-confidence, desire to take risks are characteristics of the career adaptability (Bettina, 1996).

"Career planning is the process of identifying the steps to be covered for the career development and supposes the definition of the objectives, actions to be achieved, of the necessary resources (human, financial), terms, responsibilities, effective expected results, removal of obstacles" (Hahaianu, 2000).

The performed studies and statistics showed that there was a very close relation between the career choice and planning and intelligence since, if an individual has the necessary degree of intelligence and has the proper skills, then he will choose a career matching his type of personality.

According to the choice made related to the career, the satisfaction or dissatisfaction at the workplace appears and the opportunities of personal and professional development are dependent on the degree of satisfaction. The satisfaction from the career point of view comes only when a person reached a certain threshold of happiness related to the choices made at the workplace. For instance, somebody may have made a very good choice as for the career, but he/she may deal with certain conflicts at the actual workplace or with any other unpleasant situations. Therefore, the actual workplace may be or may not be in accordance with the choices in the career field. This may influence the future choices and options of the individual, digressing from the initial plan of the career.

Further, after the individual review, the employee will be able to make a review also as for the "convergence and divergence between the career orientation, specific exigencies/rewards of the professional environment" and thus the employee's attitudes and behaviour towards work shall be determined. (LEFTER et al., 2012, p. 245).

\section{Study}

If approximately 50-60 years ago, studies showed that about $2 \%$ of employees were interested in a personal and professional development helping them in their career but also their everyday life, nowadays we meet more and more individuals willing to know better their potential and possibilities in order to make the best decisions of their life, to create a realistic career plan, but also to have particular, personal and professional performances. 
In this paper I intended for the studies performed among the healthcare staff to highlight also elements related to their personal development, in this case the development of physicians who are at the beginning of their career in Romania. We will review as much as possible also the opportunities that are granted by the Romanian healthcare system.

The study information was excerpted from questionnaires, containing questions that make direct references to the factors that involve the personal development. The individuals involved in this study are from the healthcare field.

This study follows three objectives, namely: determination of the relationship between the career choice and the employee's performance, the second objective consists in identifying the relationship between the satisfaction in career and the employee's performance. And last but not least, the third objective refers to the identification of factors influencing and inspiring each person individually for making certain decisions in career.

The purpose of this study is to understand the decisions related to career and to highlight certain features related to the employee's performances.

The study that I performed is based firstly on the research and identification of factors that are important for the development of the career plan for young physicians. Thus, within this quantitative study, the satisfaction and decision in career are independent variables, while the employee's performance would represent a dependent variable.

The research paper was made on 109 physicians, with various medical specialties, both of the public and private sector. When handing-over the questionnaire, they were insured on the confidentiality of the earned data and on the fact that such information shall be used only for this research study. The questionnaire objective was to collect information from physicians on their degree of satisfaction related to the work environment and the workplace generally.

The data and information earned as a result of the questionnaire were summarized and I will present a part of the earned results. I mention that the questionnaires were filledin by resident physicians and permanent physicians within the following healthcare facilities: Bucharest Emergency Clinic Hospital, Bucharest Central Military Emergency University Hospital, "Sfanta Maria" Clinic Hospital of Bucharest, Colentina Clinic Hospital and Regina Maria Health Private Network.

For the beginning, making reference to the financial benefits, the respondents answered in equal percentages both that they are content and discontent on the salary proportionality to the held position.

The great majority of the respondents (94\%) are aware on the job duties coming to them and they know the expectations related to them at the workplace.

As for the conditions provided at the workplace, the respondents answered in a ratio of (74\%) that they have a high volume of work and the work conditions provide them with a certain comfort. One of the motivational factors leading to the increasing satisfaction at the workplace is also the certitude that the provided work will be useful, productive and will result in the development of the team and of the establishment.

Thus, $81 \%$ of the respondents answered that their work has an important contribution to the entire department. Therefore, there is no great desire to try other careers ( $77 \%$ answered negatively as for giving up at their career).

However, they do not wish for their children or close persons this type of career, probably comparatively to other fields that develop presently more and offer more benefits (IT, services etc.). 
74\% of the respondents state having attended trainings and professional training courses for the development of their career. Also, when asked about the remuneration offered in consistence with the held position, $43 \%$ answered affirmatively, 50\% negatively, and $6 \%$ answered "I don't know".

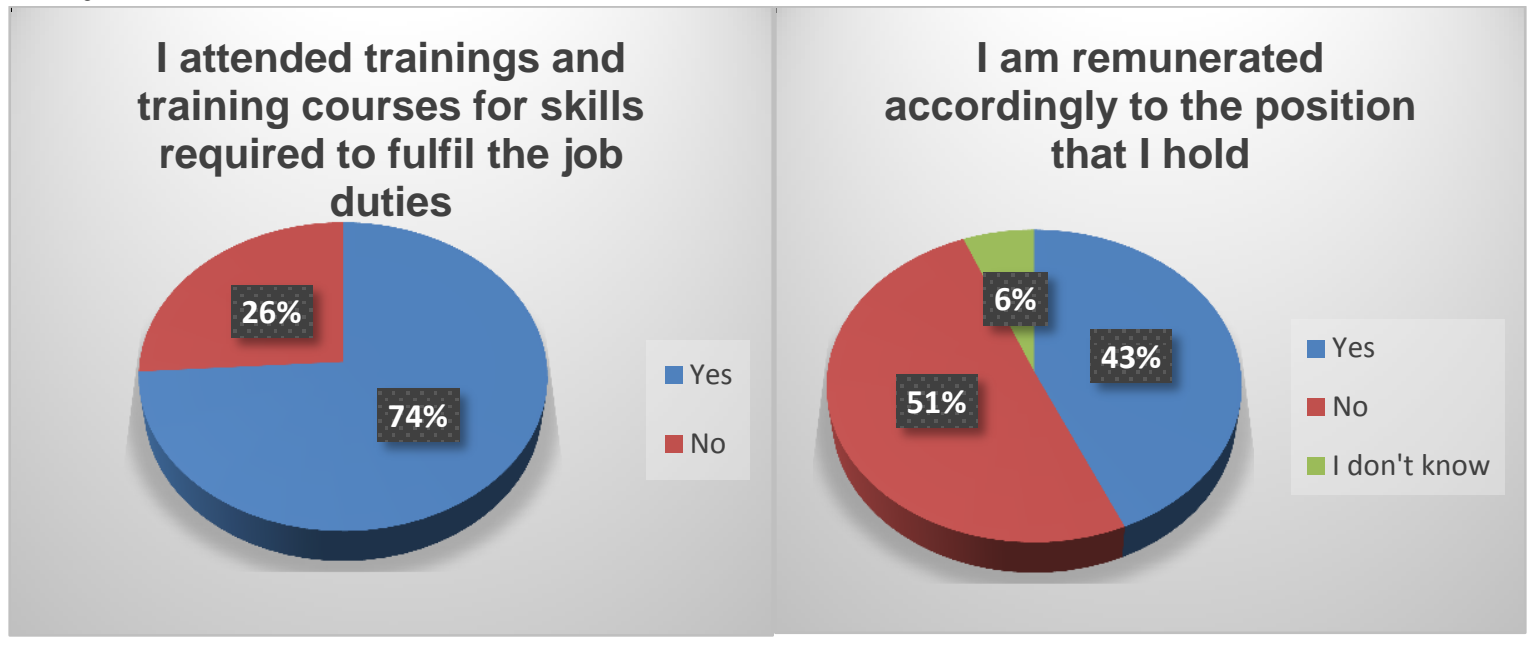

PICBE $\mid 394$

Figure 1 and 2. Questionnaire

Own source.

The questionnaire contained a question referring to benefits, I received unexpected answers within the meaning that on top of preferences as for the wanted benefits there are mentioned: benefits of pension (51\%), annual paid leave (49\%), healthcare services (39\%) and obviously flexible working hours (50\%). A very low number (10\%) answered that there is no need of necessary improvements in this respect.

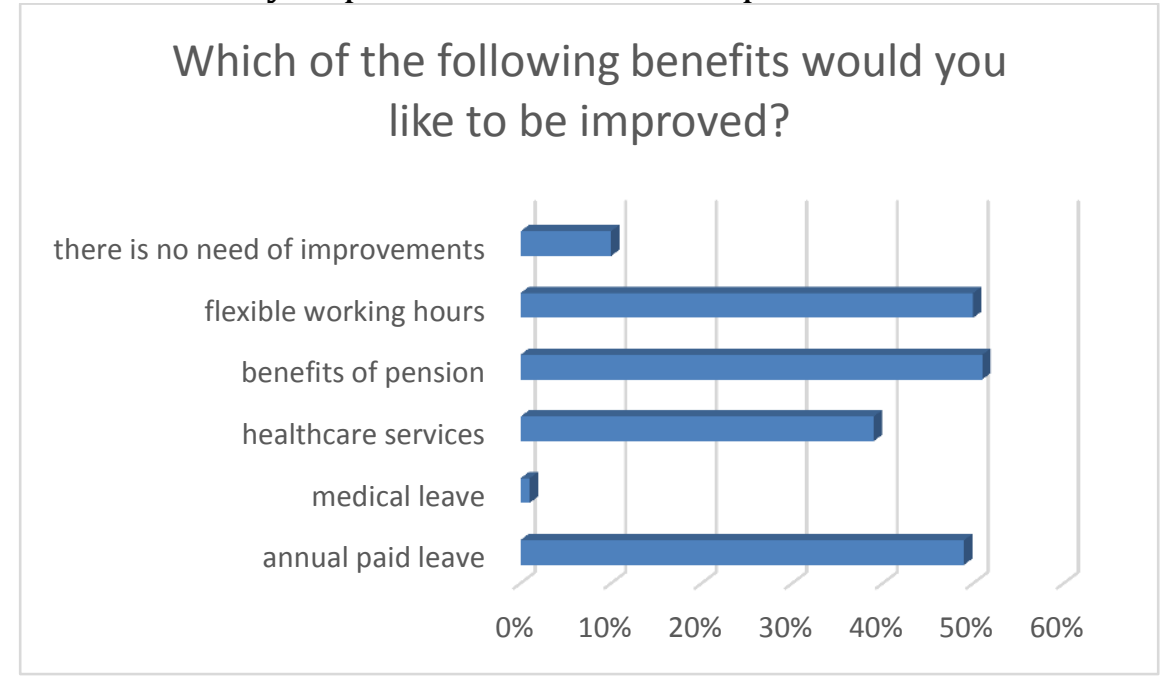

Figure 3.. Questionnaire

Own source.

Other surprising answers, considering the actual situation as well as the migration trend of physicians, were at the question related to the search for a workplace, $43 \%$ answered that they did not search and 36\% told that they would apply if opportunities occur. 


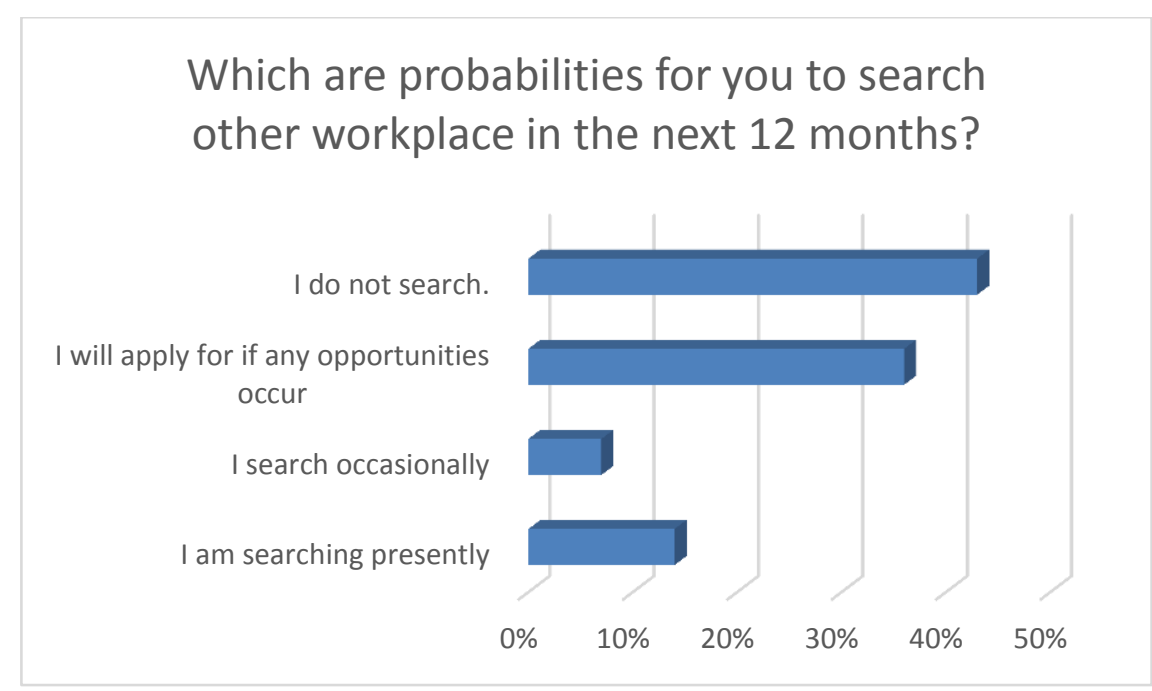

PICBE | 395

Figure 4. Questionnaire

Own source.

According to the received answers, we may conclude that the respondents did not choose the career of physician due to the influence or friends or fellows and either "out of a favour". Neither their parents' career represented a factor of great influence, only $17 \%$ of the respondents answered that their parents career had counted a lot, and $31 \%$ answered that they had been influenced a little. Thus, at the questionnaire, $29 \%$ of the respondents stated having been influenced greatly by teachers and $45 \%$ less. If regarding the influences within family or friends environment, the answers were not quite positive in high ratio, the respondents were more strongly influenced by school, teachers, visits and discussions in the field.

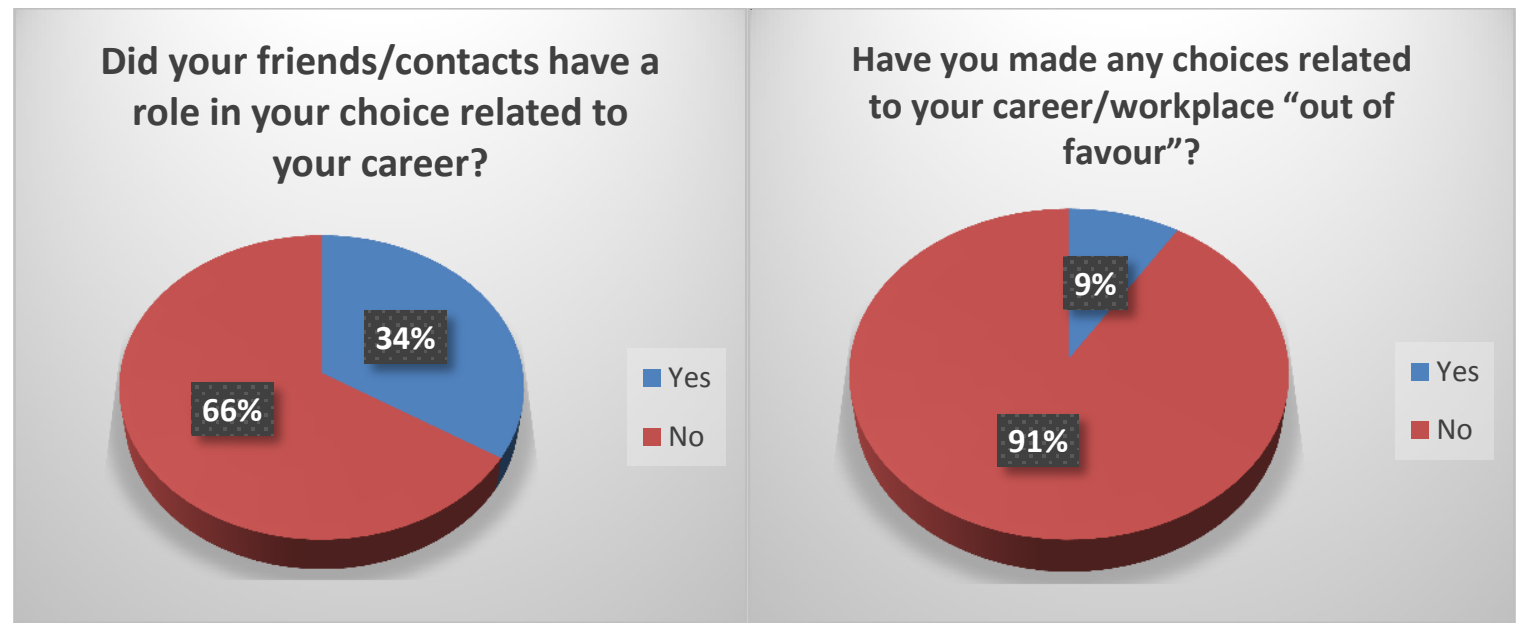

Figure 5 and 6. Questionnaire

Own source. 


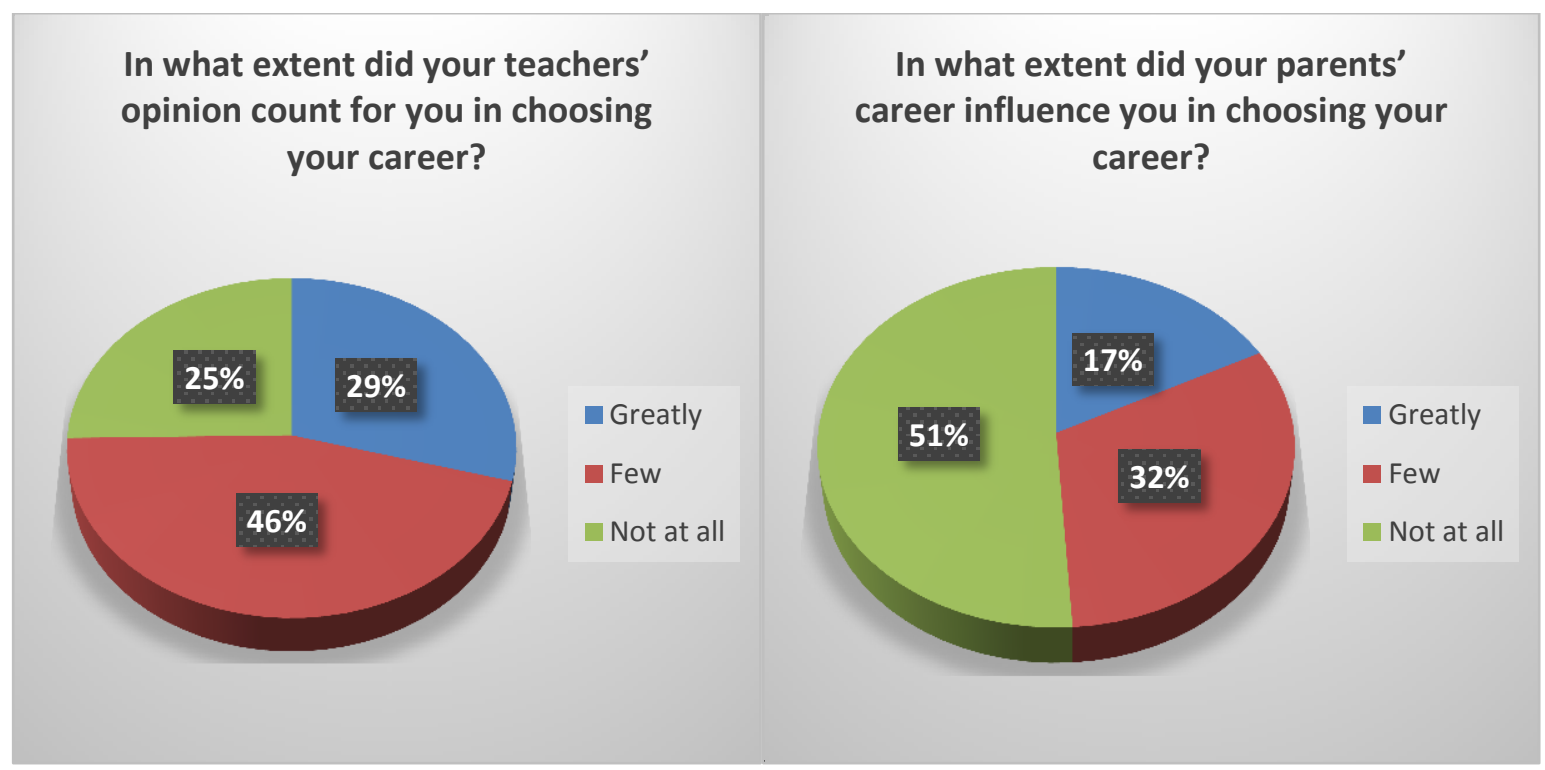

PICBE | 396

Figure 7 and 8. Questionnaire

Own source.

Another question of the questionnaire refers strictly to the factors that reasoned the respondents to choose a carrier of the healthcare field. As a first and major remark, salary was not a decisional factor, which proves that for the beginning the choice of a medical career is based firstly on factors such as: membership within an environment under continuous development or a work environment with challenging situations and duties and the financial benefits shall hold a second place.

As for the performance correlation to the satisfaction and remuneration, by interpreting the received results, I did not obtain any close relation, so the performance in the medical career in Romania is not given by the earned remuneration and further by the satisfaction offered at the workplace. Choosing a career in the healthcare field depends less on remuneration and more on providing non-salary benefits, such as the opportunity of providing programmes of personal development and working environments according to the international standards.

\section{Conclusion}

In conclusion, there is an actual and detailed theoretical support for the development of the professional career management and the personal development of employees. The need to use the theoretical support in the elaboration of some strategies for the human resource development is clear since they were elaborated further to researches and tested in various working environments and they will certainly have results in any system where their implementation would be tested.

The basic purpose of this paper is to show the actual situation of human resources in the Romanian healthcare system, more precisely the aspect regarding the beginning and development of a career for Romanian young physicians.

Also, the research was mainly intended to show some connections between the choice of the physician career, the satisfaction earned at the selected workplace and the earned performances. Even if they are subjects quite frequently encountered nowadays for 
many fields of activity, it seems that these terms and their interdependence were very few reviewed in the context of the Romanian healthcare system.

Researches showed that the choice of a career in the healthcare field is not dependent on the choices of family, friends, but more on getting a certain prestige and the perspective of obtaining an accessible and well remunerated workplace.

Human resources within the Romanian healthcare organisations need an improvement in their functional coordination, need an appropriate system to motivate the healthcare staff, need opportunities for the development of the professional career etc.

The final conclusion is that there is an acute need to find a medium and long-term strategy of human resources development in first phase and further, to find elements of their retention and development.

\section{References}

Bettina, L. B. (1996) Career Resilience. Columbus: ERIC Clearinghouse on Adult, Career and Vocational Education.

Fottler, M. D. and Bain, T. (1984) Realism of Occupational Choice Among High School Seniors: Implications for Quality of Work Life, Occupational Behaviour.

Hahaianu, L. (2000) Human Resource Management, Rentrop \& Straton Publishing House, Bucharest.

Lefter, V., Deaconu, A., Manolescu, A. (2012) Human Resource Management, Pro Universitaria Publishing House, Bucharest.

Tasica, Luminita Catalina (1997-1998). Education for career management at the early studentship, Career Counselling Department, Institute of Educational Sciences, Bucharest. 